\title{
US Open Access Life Cycle
}

\section{Key}

\section{University/Library}

Publishers/Platform Providers

Above campus

Open Access Workflows for Academic Librarians (OAWAL)

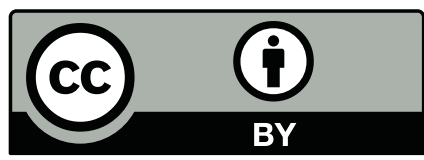

Stone, Graham and Emery, Jill (2015). US Open Access Life Cycle http://dx.doi.org/10.5920/USOA.2015

Based on the UK Open Access Life Cycle

http://dx.doi.org/10.5920/UKOA.2015

Advocacy

Models and Mandates

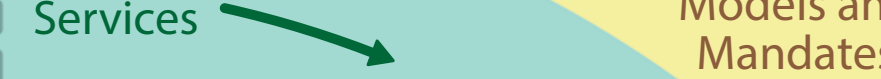
Services

Portico/

Share/ I Sherpa

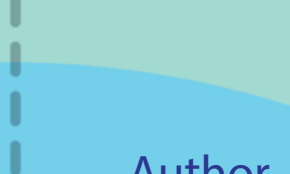

Collaboration

Tools

Statistics Publisher

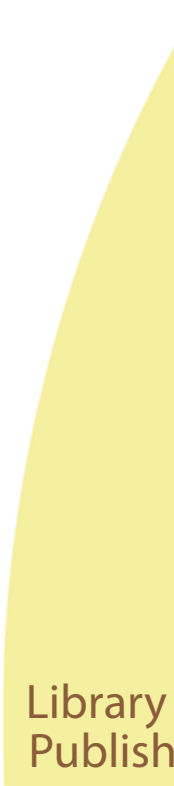

Distribution

System

Publisher

Discoverability

Repository

Publishing

Systems engines

Discovery

Services

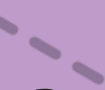

Read/Use

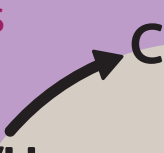

Awards
Management
System
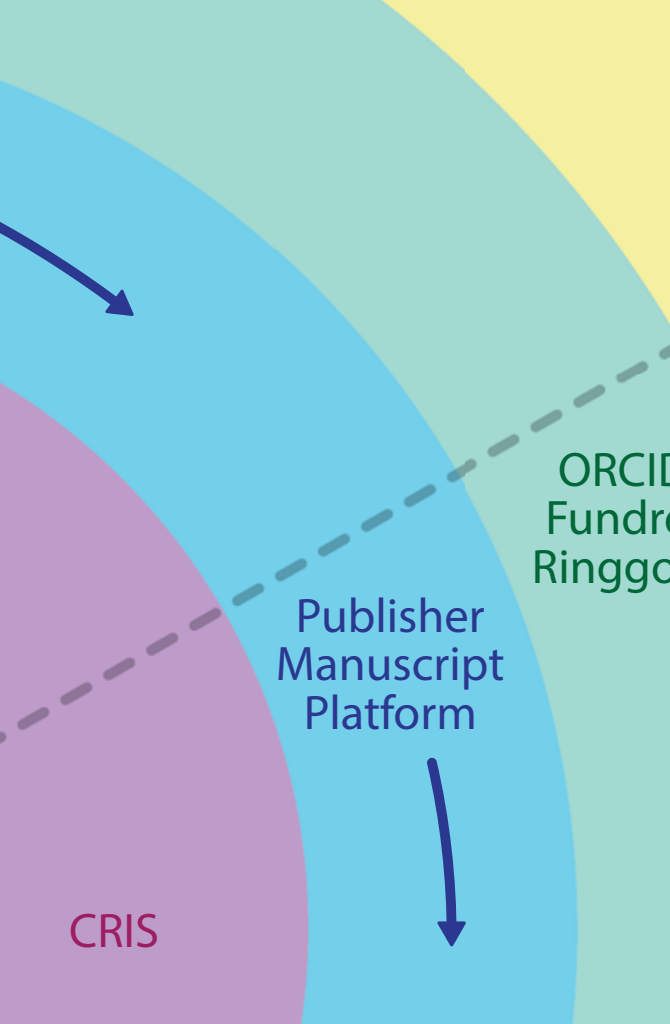

Submit

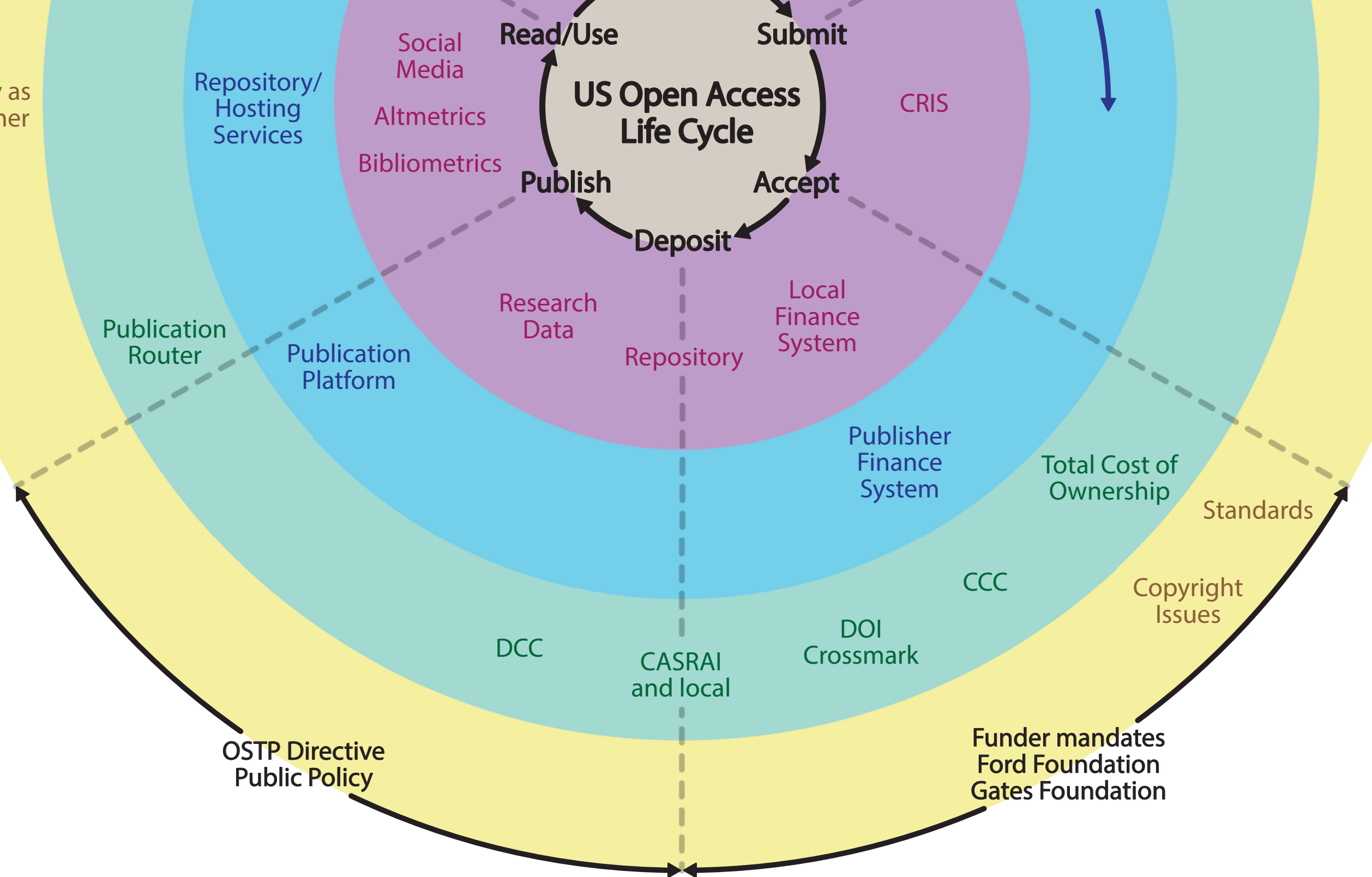

Life Cycle

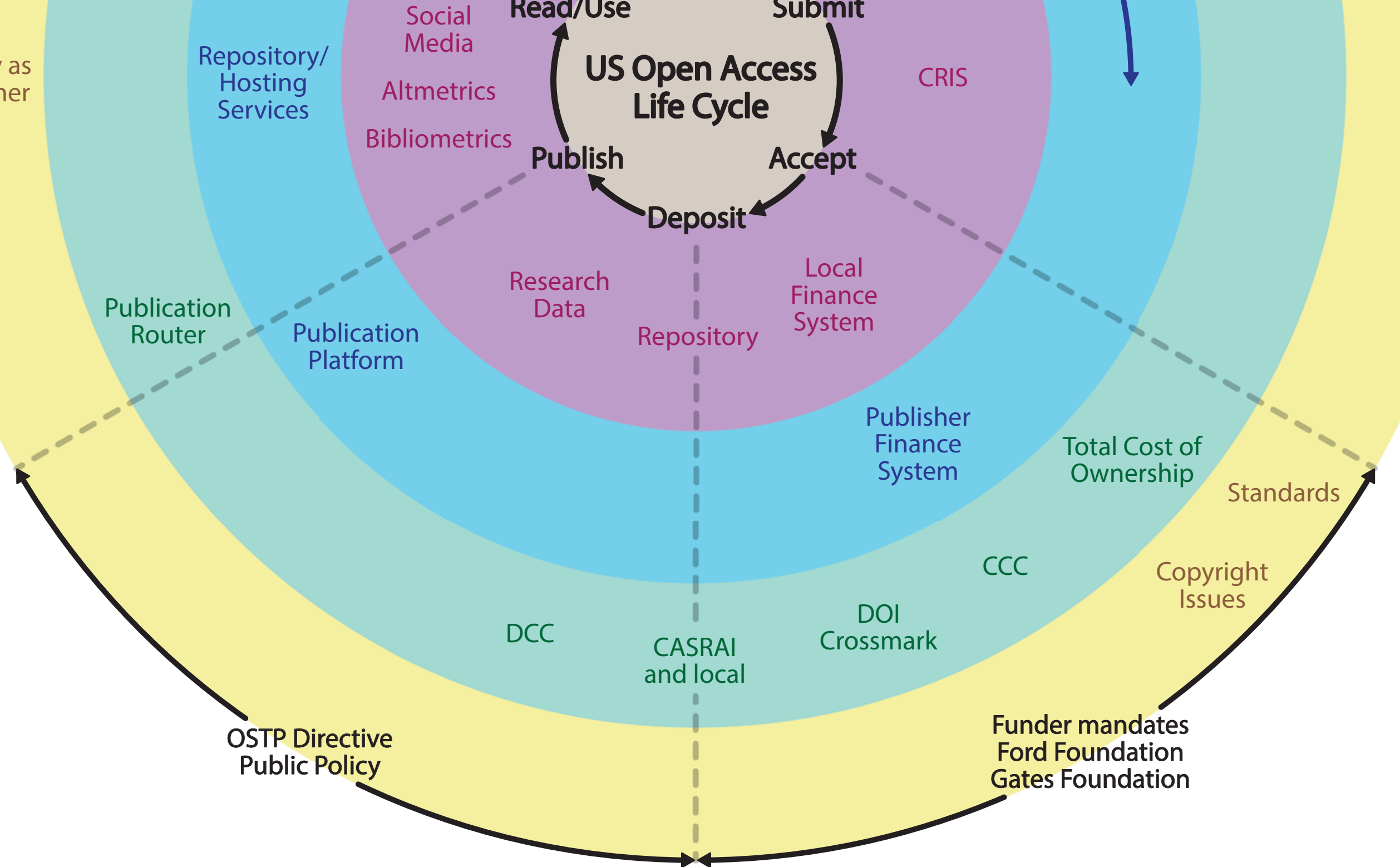

RCID inggold 